\title{
Analysis of Current Situation of Food Industry in China's Urban Area
}

\author{
Youcheng $\mathrm{Xi}^{1, *}$ \\ ${ }^{1}$ Youcheng Xi, Hwachong International School, Singapore, 269783, Singapore \\ *Corresponding author. Email: xiyoucheng730@gmail.com
}

\begin{abstract}
Covid-19 epidemic has a server impact to the whole world. Each country's industries have been affected in different degrees. At the same time, this paper mainly focuses on the impact of the pandemic to the food industry of China including the effect of the pandemic, the reaction of China government towards the decline of the food industry, as well as the prediction of the future main trend of the industry. The author found that under the epidemic situation, the food industry has been greatly affected, and the turnover of many companies has declined. Therefore, the main trend in the entire food industry is takeaway.
\end{abstract}

Keywords: Catering, pandemic, government policy, food delivery

\section{INTRODUCTION}

In the last quarter of 2019, the world-wise virus pandemic Coronavirus 2019(also called Covid-19) had burst out. Due to the severe acute respiratory syndrome coronavirus 2 (SARS-CoV-2), large amount of people passes away and each country has implied different degrees of curbing actions such as lockdown (Commonly seen in China) and limiting the frequency and the scale of social interaction events (Took place in Singapore). This article will analyze the changes in China's food industry during the COVID-19 epidemic and the factors affecting the food industry. And further discuss the impact of the epidemic on the overall economy from a macroeconomic perspective make discussion on the current situation of food retailing sector in China, including both dine-in business and take-away services. Other several subtitles this paper is going to discuss include the followings: Research and analysis of main trend of food retailing sector in China during pandemic situation. (growing/declining). Possible reasons of the growth/decline of food retailing sector will also be covered in this paper since it's useful for future prediction. Future forecast of food retailing sector and possible outcomes for rear-pandemic time period. Possible consequences toward the regional economy system under the impact of changing structure in food retailing sector and the next-step actions that needed to be carry out [1].

\section{THE IMPACT OF COIVD-19 ON THE ECONOMY AND THE FOOD INDUSTRY}

\subsection{The pandemic affects both consumers and producers in the economy}

Through the perspective of the number of confirmed cases, relevant cases began to appear in December 2019 From late January to February 2020, the number of new confirmed cases shows an explosive growth, since March 2020, the growth of the number of confirmed cases has gradually slowed down. As of July 31, 2020, the cumulative number of confirmed diagnoses nationwide was 84,337 . In this case, Consumers are the first group to be affected by the epidemic. For their own safety, people tend to reduce the frequency of going out and reduce consumption. At the same time, due to the dependence of the food industry on consumers, many companies have experienced unsalable commodities, and insufficient demand has also led to the stagnation of the entire economy[2][3]. 


\section{China's GDP(2019-2020)}

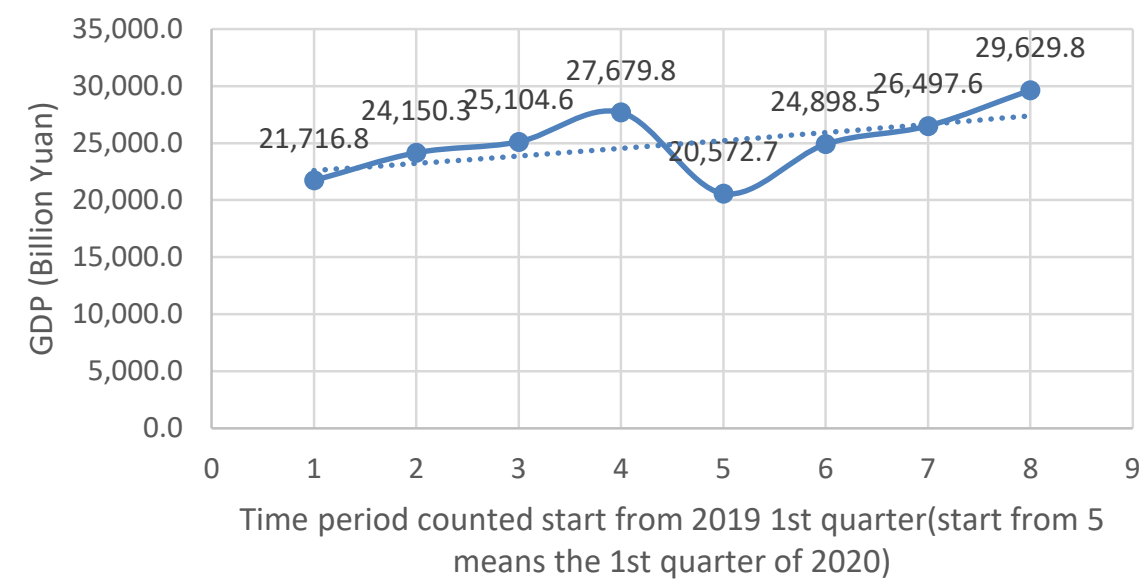

Figure1 China's GDP trend graph

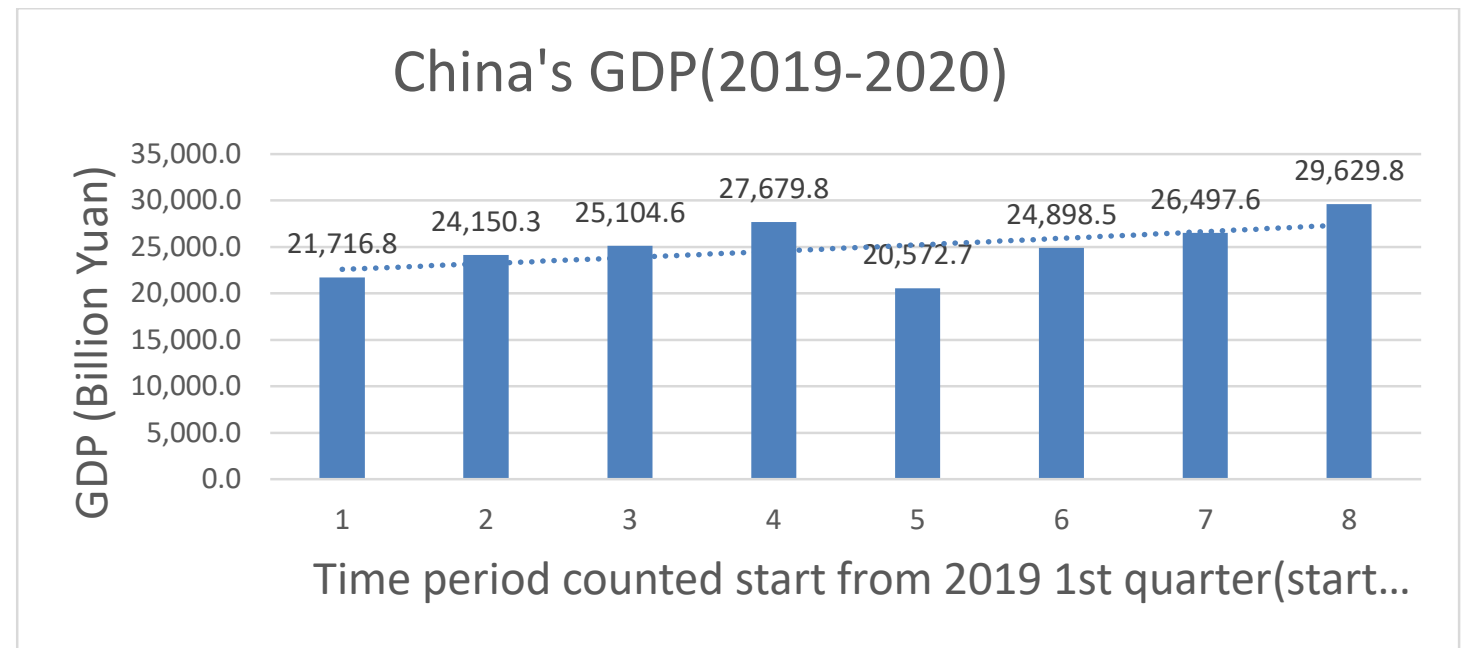

Figure2 Bar graph of China's GDP from 2019-2020

\subsection{Pandemic affect whole country's}

Total GDP of 2019: $¥ 986,515.2$ (B)

Total GDP of first three quarters in

2019: $¥ 709,717.2$ (B)

GDP of first quarter in 2020:

$¥ 205,727$ (B)

Figure3 GDP data processing procedures

By comparing the difference between the GDP of Oct. to Dec. 2019 and the GDP of Jan. to Mar. 2020, it is obvious that the specific GDP has decreased by 71,071 (B)yuan, this is likely to be the evidence of the diseconomy impact to the country, included but not only the food industry. Under this extreme situation, both supply and demand side of food industry are affected, and the level of impact depend on the risk awareness of people. In the early stage of the pandemic, because of the stressfulness acting from the new disease, even most of the people yet have the same income level and maintain same level of purchasing power, people tend to keep the money instead of consumption, the total aggregate demand in the economy generally decreased. With the gradual control of the virus, people's consumption desire is gradually rising in a certain degree, the consumption level gradually increases back to the normal level. On the contrary, from the perspective of supply, sales revenue has been drastically reduced, and forced many of the businesses in food industry to exit their market since the continuously stagnant sales revenue no longer meet the cost of production. 


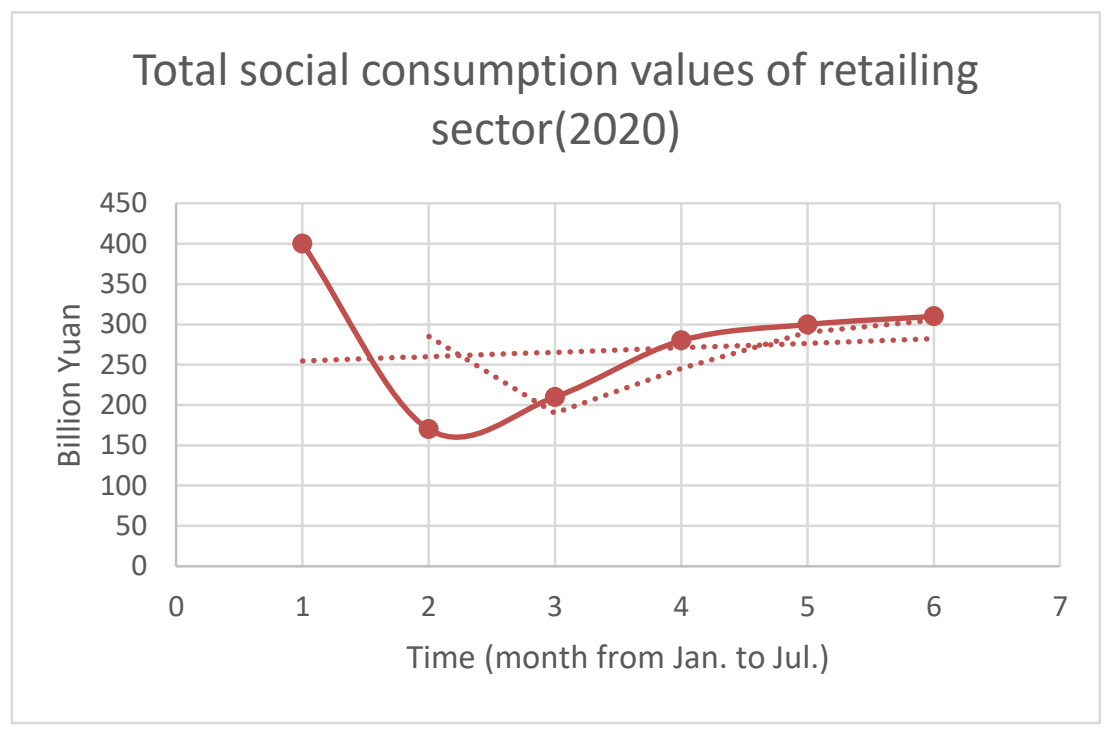

Figure4 Graph of National Bureau of Statistics of China ) [4]

According to Figure4, from January to July 2020, the national monthly catering income was significantly lower than the level of the same period in 2019, and the rate of decline curve showed a negative gradient slope from left to right. This shows that the decline in the national catering income gradually decreases with the further developments of the pandemic. It proves that the impact of the covid-19 pandemic on the catering industry is obviously staged. The outbreak of the epidemic in China coincides with the Spring Festival holiday. Therefore, this situation not only undermined the "Spring Festival Golden Week" of the food industry (a period of substantial increase in normal sales income of food industry companies), but also caused a significant drop in the turnover of food companies. At the same time, the existence of fixed costs such as inventory, rent, and salary has further plunged businesses into a serious shortage of cash flows. Relevant policies were then successively implemented, and the catering industry resumed their production and get back to work one by one, finally the turnover has gradually picked up.

\subsection{Existing problems among food industry under pandemic}

\subsubsection{Cash flow shortage}

According to the China Culinary Association's "Report on the Impact of the Covid Epidemic on China's Catering Industry in 2020": 26.8\% of catering businesses said that their cash flow has been already unable to flow elastically, and $37.0 \%$ of the catering firms reported that their cash flow are in extremely shortage and would only able to last for about 1 to 2 months. Besides $22.9 \%$ of catering businesses said that their cash flow are relatively short, which can last for 3 to 4 months. As the epidemic continues, some small and medium-sized catering merchants will be on the verge of bankruptcy, and some leading catering companies will also be in trouble.

Even the huge food industry business "Xi Bei", started to complain about their urgent situation on cash flow. Jia Guolong, Chairman of "Xi Bei" Catering Group said that according to their current stagnant sales revenues and unchanged cost expenditures, they are not able to make it for more than 3 months. [5][6]

\subsubsection{Difficulties in financing loans}

Catering companies usually have fewer fixed assets and are not high-quality and stable customers of traditional financial institutions, they rely heavily on their cash flow and consumer base, fixed assets like heavy production machines normally do not exist, food sector is more like a service provider which have little fix assets and make production on raw material(uncooked food), turn them into dishes and let the customers to consume, such labor productivity are called flow assets which cannot be counted in the assets data report, but only counted as their cost while accounting[7]. Besides, it is more difficult to obtain loans and policy support funds. When the epidemic affects revenue, it is more difficult to obtain loans.

\section{CURRENT CURBING POLICIES FROM GOVERNMENT}

Until February 20th, 727 key companies that are important for the prevention and control of the covid pandemic have obtained special reloans established by the People's Bank of China. The current total amount of 
this special reloan is $¥ 300$ billion. The People's Bank of China and relevant departments have established full-process monitoring of the use of funds for pandemic prevention and control, and strictly screened companies to ensure that the companies on the list meet the scope of support specified in the documents of the five ministries and commissions including the Ministry of Finance.

In addition to special re-lending, the People's Bank of China also continued the existing debts of enterprises, clarifying that for enterprises that have difficulties in repayment due to the impact of the epidemic, the bank must extend or renew loans to ease the imminent pressure of repayment and interest payment. Besides, further increase credit support, encourage banks to provide enterprises with incremental financial support, and at the same time, guide banks to reduce loan interest rates and reduce or exempt service fees.[8]

Since the outbreak of the covid pandemic, insurance companies have also taken multiple measurements to provide insurance claims services. Ji Yuhua, deputy director of the Policy Research Department of the China Banking and Insurance Regulatory Commission, said: "For the insured people who got affected by the epidemic, special personnel will be arranged to perform claims settlement services. According to statistics, most customers can complete the compensation on the same day after submitting the compensation, and the fastest only takes less than 5 minutes. Enterprises are also actively expanding the scope of insurance liability, including the new crown pneumonia epidemic into the scope of accident insurance and disease insurance, and abolishing "specific infectious diseases" and other exemptions.So far, 68 property insurance companies have developed more than 600 insurance products by expanding product liability. Under the premise of not increasing premiums, 70 personal insurance companies extended the scope of liability for 1,210 products to the covid pandemic, benefiting a large number of policy holders."[2]

After all these policies are implied, most of the medium or small corporations find it's easier to carry on their original business, and since they can payback the interest later, they have more time to relocate their production distribution in order to better adapt this special pandemic situation[9].

After all these policies are implied, most of the medium or small corporations find it's easier to carry on their original business, and since they can payback the interest later, they have more time to relocate their production distribution in order to better adapt this special pandemic situation.[10]

\section{THE FUTURE DEVELOPMENT TREND OF THE FOOD INDUSTRY}

According to the current situation, possible future outcome of food industry could be highly depending on "take-away" services.

\subsection{Food delivery services experienced a huge growth during the rear period of the pandemic}

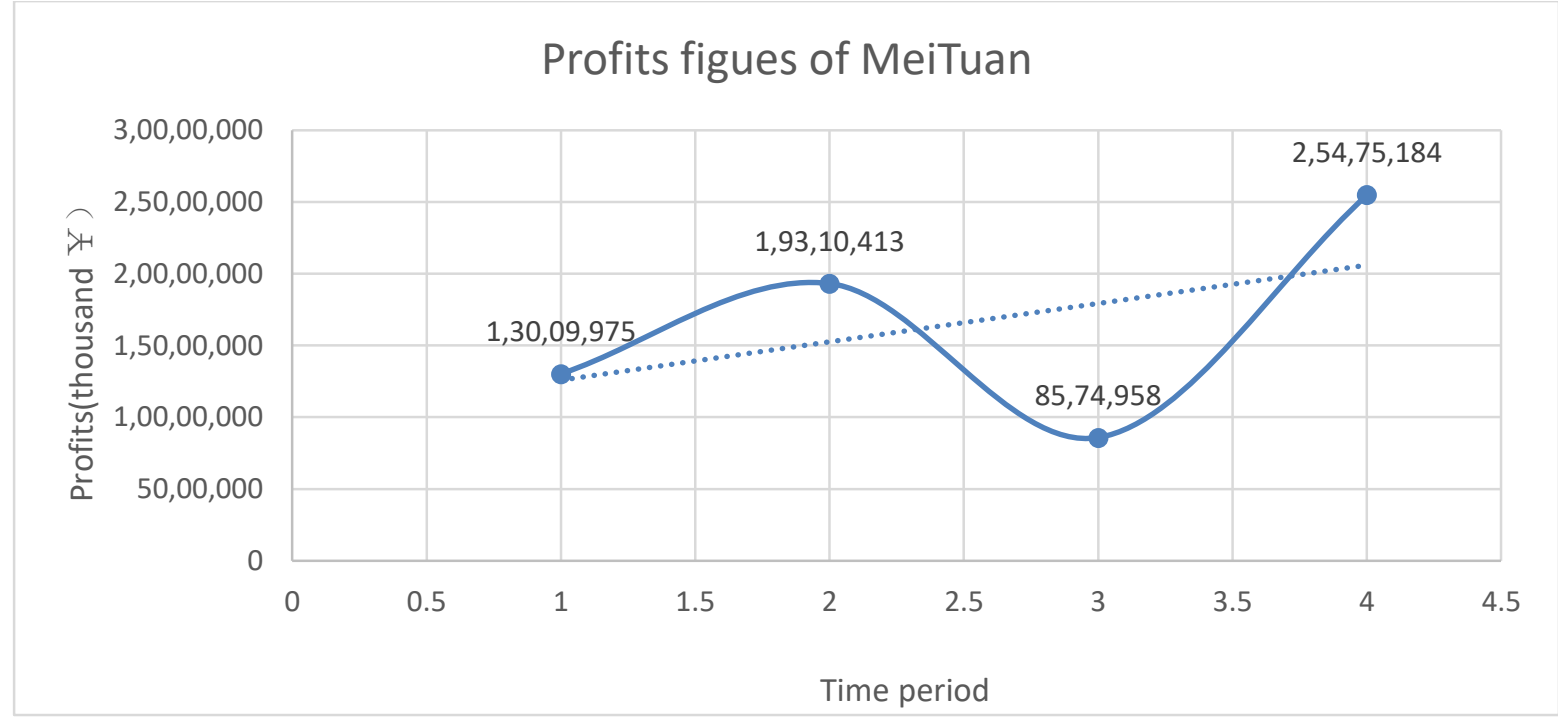

Figure5 Profit Figureures graph form Mei Tuan's official site [11]

Under the great trend of the accelerating food delivery services of food, many businesses gradually pay more attention on their take-away services. While the advantages of take-away increasing dramatically, some companies successfully reached to an ever-high level. Mei Tuan is one of the biggest food delivery business in China and according to the profits graph above, it shows that its profits situation indeed faced a huge decrease during the beginning stage of covid pandemic. But soon later, during the rear period of the pandemic ( 3 rd\&4th quarter of 2020), the sales revenue increased rapidly and lead to a huge jump for gross 
profits, much higher than the profits earned during the same time period of 2019. This fugue is likely to be the evidence of saying that food delivery sector is the main trend of food catering industry.

\subsection{Total imported value increased against the trend of pandemic.}

Table 1. Few Examples of Half-year Import Details of China 2018-2020[12]

\begin{tabular}{|c|c|c|c|c|c|c|}
\hline & \multicolumn{2}{|l|}{2018} & \multicolumn{2}{|l|}{2019} & \multicolumn{2}{|l|}{2020} \\
\hline $\begin{array}{l}\text { Name of } \\
\text { the product }\end{array}$ & Imported quantity(t) & Amount (US\$) & Imported quantity(t) & $\begin{array}{l}\text { Amount } \\
\text { (US\$) }\end{array}$ & Imported quantity(t) & $\begin{array}{c}\text { Amount } \\
\text { (US\$) }\end{array}$ \\
\hline Beef & 456437 & $2,114,758$ & 697,529 & $3,254,871$ & $1,000,000$ & $5,198,253$ \\
\hline $\begin{array}{l}\text { Cooking } \\
\text { sugar }\end{array}$ & 1380000 & 539579 & 1070000 & 374,292 & $1,240,000$ & 460,349 \\
\hline Cooking oil & 2770000 & $2,143,952$ & 3990000 & 2675875 & 4030000 & 3022741 \\
\hline
\end{tabular}

Table1 shows that China's main imported goods economy tend to growth back to the normal production including beef, sugar and cooking oil. The increasing trend proved that during the rear period of pandemic,

level and consumption level also rise back to normal step by step.

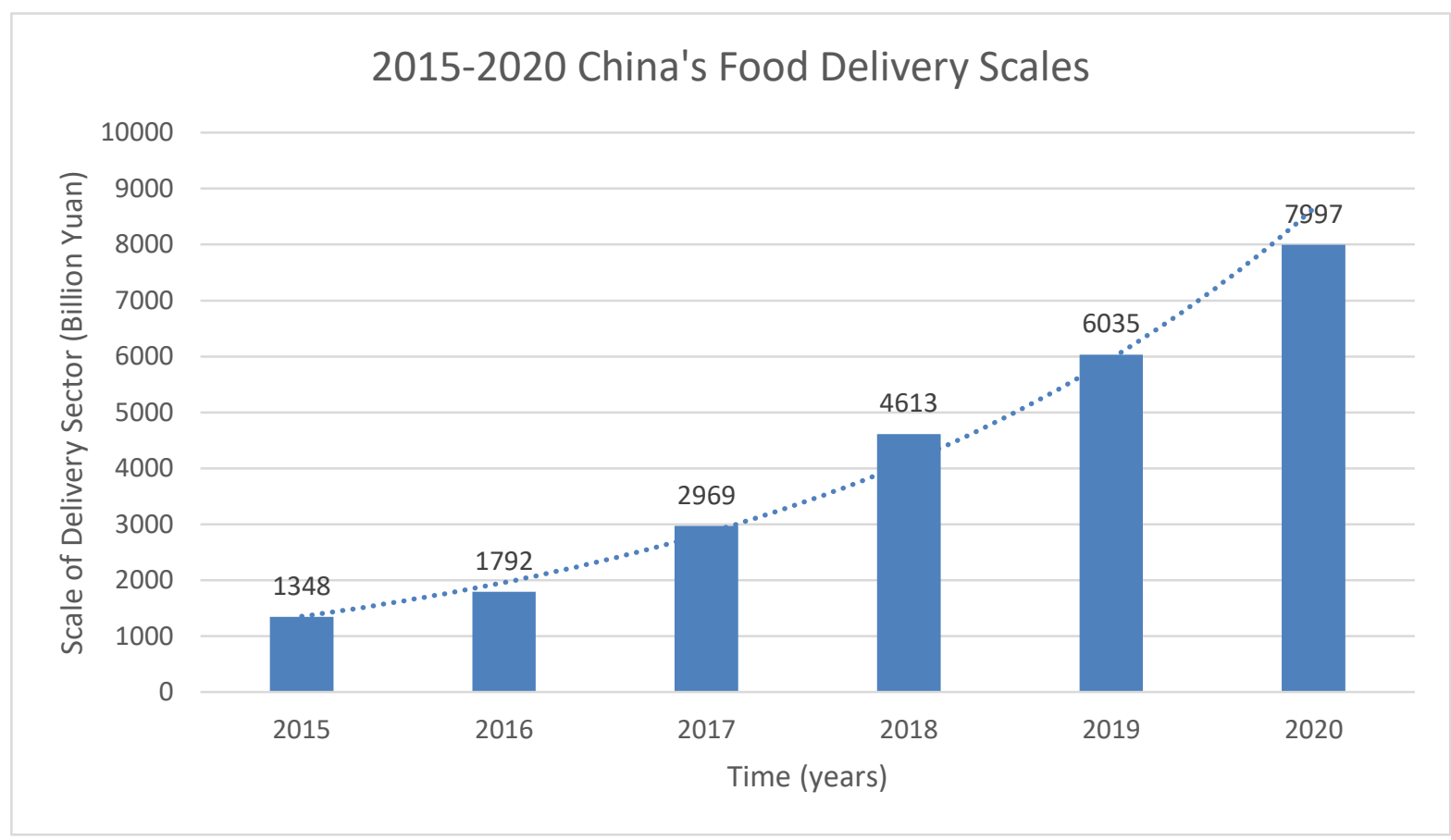

Figure6 Growth of food delivery sectors in China

As it shows in Figure6, the scales of food delivery services are increasing annually, together with the assistant of Figure4, they all shows that more and more businesses in food industry, start to look forward this new route of sealing which better meets consumers needs and wants. All in all, all these data proved that food delivery will be the main trend of catering market.

\section{GOVERNMENT INTERVENTION}

Under the changing situation, advises for government to take into account could be encouraging more sufficient policies such as cutting tax or interest rate for certain businesses in food industry, focus on those businesses that really need the subsidies and avoid wasting budget on those well-heeled companies which did not actually affected by the pandemic. [13] By relocate the budget efficiently, government will be able to maintain a sustainable degree of national debt and minimize the possibility of getting into budget deficit troubles. Besides, possible consequences of encouraging delivery food like health problems should also be covered in the future. It is recommended that the government conduct a consumer survey of customers who always eat takeout instead of dine-in (if the research is also focused on the food industry), focusing on the health problems and related hidden dangers of citizens after long-term consumption of these foods With higher populations with low health condition, their total overall productivity to the economy thus tend to become smaller and become lower in production efficiency (no matter what job one is taking, there will always be a production processing within it), predictions 
like torpor economy growth should be very easy to obtained in this case[14].

\section{CONCLUSION}

All in all, according to all the investigation and data collections, final result come up with the main trend of the whole food industry----food delivery. Pandemic compel people to stay at home instead of go out and consume, this caused a huge problem since consumers always lead to concept of demand and demand always plays an important role in every country's economy, including but not only China's. According to the current situation, food delivery will be one of the major segmentations for food catering businesses to further growth at and also the fastest route to get out the stagnant period. By sequence, government should pay more attention on those businesses with relatively urgent cash flow, cut down the interest rate and elongate the due date of interest payment. However, in this paper, there do have some parts which are not covered. The accuracy of data collected are limited by writer's current ability of accessing to the latest data, while calculating GDP, possible inaccuracies caused by hidden economy such as illegal events (drug deal) or social volunteering works are not counted in GDP so may not reflect the real economy outcome while using GDP as a calculate model. For further researches of the outcome of the economy at the end or after the pandemic, researchers are advised to focus more on the consequences of growing food delivery sectors, citizens health issues after eating takeaway food for a long time can be talk about.

\section{ACKNOWLEDGMENTS}

This paper required help from essay teaching assistant, Hayley, Special thanks. Besides, paper wrote under great supportive by my family and they always being so supportive to my career, so thanks my family, as well as all my confidant friends who provide a lot of use very useful information.

\section{REFERENCES}

[1] Zhang Xiaheng. The impact of the new crown pneumonia epidemic on my country's small, medium and micro enterprises and its response[J]. China Circulation Economy, 2020 (3): 26-34.

[2] Yang Bo, Xia Xiaojun, Chen Yuanyuan. Catering industry under the new crown pneumonia epidemic: shock and differentiation[J]. Journal of Hohai University (Philosophy and Social Sciences),2021,23(1):31-40.

[3] Wang Yongning, Xu Xiaoqin, He Shuangyu. Economic analysis of SARS-like crisis on demand suppression[J]. Business Research, 2004(12): 5-8.
[4] Gov.cn 。 2021.Data details_Data_China Government Network. [Online] Available at : <http://www.gov.cn/shuju//hgjjyxqk/detail.html?q= 6>[2021 年 6 月 29 日访问]。

[5]Society.people.com.cn. 2021[online] Available at: <http://society.people.com.cn/n1/2020/0210/c100831580448.html?from=timeline \&isappinstalled $=0>$ [Accessed 29 June 2021].

[6] Xu Yongmei. Bottlenecks and countermeasures for the development of small and medium-sized enterprises in my country $[\mathrm{J}]$. Ningxia Social Sciences, 2015 (6): 99-100.

[7] Cao Yonghua. Development of SMEs and financial support [J]. Journal of Zhongnan University of Economics and Law, 2006 (4): 92-95.

[8] Brandt, Loren, and Xiaodong Zhu. "Redistribution in a decentralized economy: Growth and inflation in China under reform." Journal of Political Economy 108.2 (2000): 422-439.

[9] International Online Report, Qu Wenbin, (Feb 24th 2020)

[10] Gov.cn. 2021. Notice on Further Strengthening Financial Support to Prevent and Control the Novel Coronavirus Pneumonia Epidemic [online] Available <http://www.gov.cn/zhengce/zhengceku/2020-02/0 1/content_5473639.htm> [Accessed 29 June 2021].

[11] About.meituan.com. 2021. Meituan News Announcement_Financial Reports_Prospectus Documents_Investor Diary-Meituan Official Website. [online] Available at: <https://about.meituan.com/investor> [Accessed 29 June 2021].

[12] 2021. [online] Available at: <http://www.customs.gov.cn/customs/302249/3022 74/302277/index.html> [Accessed 29 June 2021].

[13] He Jun. The current shortcomings and adjustment directions of my country's SME promotion policies [J]. Zhongzhou Academic Journal, 2016 (10): 31-36.

[14] $\mathrm{Wu}$ Liyun. Government subsidies and financing constraints of small and medium-sized enterprises-a study of heterogeneous effects and mechanisms [J]. Business Research, 2019 